\title{
Synthesis, spectral properties and thermal behaviour of zinc(II) acetylsalicylate
}

\author{
John N. Lambi ${ }^{\mathrm{a}, *}$, Alfred T. Nsehyuka ${ }^{\mathrm{a}}$, Nkongho Egbewatt ${ }^{\mathrm{b}}$, \\ Lázaro F.R. Cafferata ${ }^{\mathrm{c}}$, Alejandro J. Arvia ${ }^{\mathrm{d}}$ \\ a Inorganic Chemistry Laboratory, Chemistry Department, Ecole Normale Supérieure, University of Yaoundé I, Yaoundé, Cameroon \\ ${ }^{\mathrm{b}}$ Chemistry Department, University of Buea, Buea, Cameroon \\ ${ }^{\mathrm{c}}$ Laboratorio Ladecor, Facultad de Ciancias Exactas, Universidad Nacional de La Plata, 1900 La Plata, Argentina \\ d Instituto de Investigaciones Fisicoquímicas Teóricas y Aplicadas (INIFTA), Universidad Nacional de La Plata, 1900 La Plata, Argentina
}

Received 22 September 2001; received in revised form 30 May 2002; accepted 5 June 2002

\begin{abstract}
The thermal behaviour of zinc(II) acetylsalicylate $\left[\mathrm{Zn}(\mathrm{acsa})_{2}\left(\mathrm{H}_{2} \mathrm{O}\right)_{2}\right]$ with respect to phase transitions, pyrolysis both in air and inert $\left(\mathrm{N}_{2}\right)$ atmosphere, and product identification has been investigated. The complex was synthesised by metathesis in hot ethanol solution using aspirin (acetylsalicylic acid) as precursor and characterised via electronic and IR spectral analyses. Optical observations showed that the white salt does not undergo a direct transition from the solid to the liquid phase but rather goes slowly through an intermediate mesophase around $80^{\circ} \mathrm{C}$ before melting rapidly to the brick-brown isotropic liquid around $134-136^{\circ} \mathrm{C}$. No liquid crystalline phases are however formed. This result was complemented by that from thermogravimetric (TG) studies in the ca. $25-600^{\circ} \mathrm{C}$ range, which showed three main weight-loss phases of 8.0, 50.0 and 14.0\% (around 200, 250 and $400{ }^{\circ} \mathrm{C}$ ) corresponding, respectively, to the elimination of $\mathrm{CO}_{2}$, xanthone and acetic acid. The pyrolysis products, as identified using a combination of instrumental (GC-MS) and wet chemical techniques are: $\mathrm{CO}_{2}$; non-stoichiometric zinc oxide, most likely in the form: $\mathrm{Zn}_{1+x} \mathrm{O}$ (where $0.0000 \leq x \leq 0.0003$ ); and a mixture of organic products resulting from further decomposition, charring and other attendant thermal effects at the relatively high temperatures $\left(\mathrm{ca} .600^{\circ} \mathrm{C}\right)$ involved. Six of the principal organic products were identified and included salsalate and benorylate which are pro-drugs of salicylic acid, a well-known pharmaceutical.
\end{abstract}

(C) 2002 Elsevier Science B.V. All rights reserved.

Keywords: Acetylsalicylate; Pyrolysis; Mesophase; Metathesis; Themogravimetry; Pro-drug; Precursor

\section{Introduction}

While acetylsalicylic acid (aspirin), a well-known century-old chemical pharmaceutical [1], enjoys so

\footnotetext{
* Corresponding author. Present Address: B.P. 30084, BiyemAssi, Yaoundé, Cameroon. Tel.: +237-231-73-34; mobile: +237-757-73-26; fax: +237-231-73-34.

E-mail addresses: jlambi@yahoo.com,jlambi@cenadi.cm (J.N. Lambi).
}

much popularity worldwide, little is known of its inorganic derivatives outside the soluble salts [2] formed mainly with $\mathrm{Na}, \mathrm{K}, \mathrm{Mg}$ and choline. These soluble salts are sometimes employed as alternatives to aspirin and/or salicylic acid whose absorption levels are known to be low in the predominantly acidic/aqueous medium of the stomach. On the other hand, several pharmaceutical and structural studies have been undertaken on the metal complexes of some other substituted salicylic acids [3] and salicylic acid itself [4,5]. 
However, while the copper-aspirin complex has been reported to be a better anti-inflammatory agent than aspirin itself [6], the only study reported so far in the literature for the zinc-aspirin complex is on its synthesis and crystal structure [7]. The synthesis was carried out in water by treating the sodium salt of aspirin with various salts of zinc (e.g. $\mathrm{ZnCl}_{2}$ and $\mathrm{ZnClO}_{4}$ ) and the resultant complex crystallised as zinc(II) acetylsalicylate $\left[\mathrm{Zn}(\mathrm{acsa})_{2}\left(\mathrm{H}_{2} \mathrm{O}\right)_{2}\right]$ complex and characterised using IR and ${ }^{1} \mathrm{H}$ NMR spectroscopies. The crystal structure, as determined by X-ray crystallography, was found to be a severely distorted tetrahedral coordination of the zinc ion with two monodentate carboxylate groups and two water molecules as ligands [7]. No study has yet been reported in the literature on the thermal behaviour of the zinc-aspirin complex.

In this paper, we report the results of the thermal behaviour of the $\mathrm{Zn}(\mathrm{acsa})_{2}\left(\mathrm{H}_{2} \mathrm{O}\right)_{2}$ with respect to phase transitions, thermal decomposition (pyrolysis) both in air and inert $\left(\mathrm{N}_{2}\right)$ atmosphere, and product identification. We synthesised the complex using another method [8] and hope to show in this paper that apart from X-ray analysis [7] employed earlier, electronic and IR spectral analyses could also be used to determine the coordination and bonding modes between the $\mathrm{Zn}^{2+}$ ion and the aspirin ligand. The inorganic decomposition product obtained $(\mathrm{ZnO})$ has numerous well-established applications especially in electronics [9] while two of the six principal organic decomposition products identified (salsalate and benorylate) are pro-drugs [10] of salicylic acid, a well-known pharmaceutical [1].

The present study is, in fact, part of on-going research in our laboratory $[8,11]$ geared mainly towards the systematic thermal characterisation of metal-organic systems with a potential to generate electronic materials upon pyrolysis. It is, also, partly geared towards stimulating interest in research in the near-barren domain of non-medicinal applications of aspirin.

\section{Experimental}

The acetylsalicylic acid (aspirin), zinc nitrate and ethanol (absolute, 99/100\%) used for the preparation of the $\mathrm{Zn}(\mathrm{acsa})_{2}\left(\mathrm{H}_{2} \mathrm{O}\right)_{2}$, as well as the acetone and toluene used respectively for washing and recrystallis- ing the aspirin salt, were all of analytical grade. On the other hand, the sodium hydroxide pellets and the sulphuric and hydrochloric acids, which were of commercial grade, were used without further purification. Milli-Q water was used throughout.

The melting point determinations were carried out on a STUART SCIENTIFIC SMP1 melting point apparatus fitted with a booster and a thermometer $\left(0-360^{\circ} \mathrm{C}\right)$ with $1{ }^{\circ} \mathrm{C}$ graduations. For all other temperature investigations, a digital JENWAY Probe $\left(0-1200^{\circ} \mathrm{C}\right)$ was used.

The $\left[\mathrm{Zn}(\mathrm{acsa})_{2}\left(\mathrm{H}_{2} \mathrm{O}\right)_{2}\right]$ complex was prepared by metathesis [8] in hot ethanol solution, using stoichiometric quantities of $\mathrm{Zn}\left(\mathrm{NO}_{3}\right)_{2}$ and acetylsalicylic acid (aspirin) as precursor. The reaction takes place in two phases. First, the potassium salt of the acid is prepared by adding a stoichiometric quantity of potassium hydroxide pellets to $250 \mathrm{ml}$ of a hot ethanoic solution of the precursor and the zinc salt precipitated from the mixture by slowly adding, with stirring, a solution of $\mathrm{Zn}\left(\mathrm{NO}_{3}\right)_{2}$ prepared in a minimum amount of water to prevent possible hydrolysis. The resultant white precipitate was filtered off and washed with cold water, ethanol and acetone in that order. The essential steps involved in the synthesis are given in Eqs. (1) and (2):

$$
\begin{aligned}
& \mathrm{CH}_{3} \mathrm{COO}-\mathrm{C}_{6} \mathrm{H}_{4}-\mathrm{COOH}+\mathrm{KOH} \\
& \rightarrow \mathrm{CH}_{3} \mathrm{COO}-\mathrm{C}_{6} \mathrm{H}_{4}-\mathrm{COOK}+\mathrm{H}_{2} \mathrm{O} \\
& 2 \mathrm{CH}_{3} \mathrm{COO}-\mathrm{C}_{6} \mathrm{H}_{4}-\mathrm{COOK}+\mathrm{Zn}\left(\mathrm{NO}_{3}\right)_{2} \cdot 6 \mathrm{H}_{2} \mathrm{O} \\
& \rightarrow\left[\mathrm{CH}_{3} \mathrm{COO}-\mathrm{C}_{6} \mathrm{H}_{4}-\mathrm{COO}\right]_{2} \mathrm{Zn}+2 \mathrm{~K}^{+} \\
& \quad+2 \mathrm{NO}_{3}{ }^{-}+6 \mathrm{H}_{2} \mathrm{O}
\end{aligned}
$$

The zinc-aspirin salt so obtained was recrystallised from hot toluene, dried in partial vacuum at $60^{\circ} \mathrm{C}$, and the melting point and spectra (IR and UV-VIS) recorded.

The electronic (UV-VIS) and infra-red (IR) spectra of the zinc(II) aspirin salt were run at room temperature, respectively, on a Philips PU8740 Scientific UV-VIS Scanning Spectro photometer with $\mathrm{MeOH}$ as solvent and on a Philips PU9706 IR Scientific Spectrophotometer as fluorolube mulls.

The set-up employed for the thermal decomposition of the $\mathrm{Zn}(\operatorname{acsa})_{2}\left(\mathrm{H}_{2} \mathrm{O}\right)_{2}$ in inert $\left(\mathrm{N}_{2}\right)$ atmosphere has been described elsewhere [8]. The arrangement allows the inorganic and organic products to be separated 
while the gaseous products are trapped, weighed and characterised.

By modifying the eyepiece of the STUART SCIENTIFIC SMP1 melting point apparatus, it also served as a hot stage microscope for the optical observations for phase changes.

The gaseous product was identified qualitatively as $\mathrm{CO}_{2}$ by bubbling it through limewater $\left[\mathrm{Ca}(\mathrm{OH})_{2}\right]$ and quantitatively by trapping it in a previously weighed sodalime tube. The organic decomposition products were identified by GC-MS analysis as reported in a previous work [12]. With helium as the carrier gas, samples of the mixture of products dissolved in acetone were injected into a 5890 model, Series II Plus, Hewlett-Packard instrument coupled to a 5972 A model, Hewlett-Packard MSD at $179^{\circ} \mathrm{C}$ using an HP $5 \mathrm{MS}$ capillary silica-fused column thermostated at $150{ }^{\circ} \mathrm{C}$ with the injector port at $250^{\circ} \mathrm{C}$. The identity of the inorganic product $(\mathrm{ZnO})$ was obtained via wet chemical methods using both qualitative and quantitative tests.

\section{Results and discussion}

\subsection{Electronic and infra-red spectra}

The zinc-aspirin complex was characterised via the following IR bands (Table 1) after comparison with those reported in literature [7,13-15]: $1765 \mathrm{~cm}^{-1}$ (high-frequency absorption) for the acetyl group; 1635,1615 and $1600 \mathrm{~cm}^{-1}$ (multiplet, normal absorption) for the benzene ring; 1535,1493 and $1460 \mathrm{~cm}^{-1}$ (multiplet) and 1420 and $1370 \mathrm{~cm}^{-1}$ (doublet) for the assymmetric and symmetric stretching modes, respec- tively, of the carboxylic groups; and $3344 \mathrm{~cm}^{-1}$ for the water molecules. These results compare favourably with those for the same complex prepared by a different method [7] and for some zinc carboxylates of even straight chain length from $\mathrm{C}_{6}$ to $\mathrm{C}_{8}$ [15]. In the latter case [15], the splitting observed was attributed to different interactions in the crystal field. To elucidate the mode of coordination between the metal and the ligand in our complex, two different IR spectral schemes $[15,16]$ were tested. While the one [15] indicated a mode intermediate between monodentate and chelating bidentate, though with a greater inclination towards the former, the other [16] resulted in a purely monodentate bonding mode.

The peak at $299.4 \mathrm{~nm}$ in the electronic (UV-VIS) spectrum of the zinc(II) aspirin salt (Fig. 1) is being assigned to charge-transfer $\left(n-\pi^{*}\right)$ transitions from the lone pair of electrons on the $\mathrm{C}=\mathrm{O}$ : of the carboxylate grouping to $\mathrm{Zn}^{2+}[13,17]$ while the three bands at $239.9,275.8$ and $299.4 \mathrm{~nm}$ correspond to the three conjugated units on the benzene ring. The absence of any appreciable band(s) in the visible region is normal since the $\mathrm{Zn}^{2+}$ ion has a completely filled $\mathrm{d}$-orbital $\left(\mathrm{d}^{10}\right)$ and, hence, is not expected to exhibit any $\mathrm{d}-\mathrm{d}$ transitions. Furthermore, applying Woodward and Fieser rules [18] and treating the zinc-aspirin complex as a benzene derivative of general formula, $\mathrm{R}-\mathrm{C}_{6} \mathrm{H}_{4}-\mathrm{COX}$ (where $\mathrm{X}=\mathrm{OZn}$ is the parent chromophore and $\mathrm{R}=\mathrm{CH}_{3} \mathrm{COO}$, the substituent), gives $\lambda_{\max }=237 \mathrm{~nm}$, for the principal absorption peak. This value compares favourably with the empirical value of $239.9 \mathrm{~nm}$ in Fig. 1, and once more suggests that the $\mathrm{Zn}^{2+}$ ion is linked directly to the carboxylate $\left(\mathrm{COO}^{-}\right)$group via the singly-bonded oxygen as indicated in the general formula as given.

Table 1

Infrared (IR) spectral data for zinc(II) acetylsalicylate

\begin{tabular}{|c|c|c|}
\hline \multicolumn{2}{|l|}{$\begin{array}{l}\text { Absorption frequency } \\
\left(\mathrm{cm}^{-1}\right)\end{array}$} & \multirow[t]{2}{*}{$\begin{array}{l}\text { Assignment } \\
\text { (bond stretching group) }\end{array}$} \\
\hline This work & Literature $[7,13-15]$ & \\
\hline 3360 & 3344 [7], 3200-3600 [13] & $v \mathrm{OH}^{-}$ \\
\hline 1765 & $1745[7], 1735-1785[14]$ & $v_{\mathrm{h}} \mathrm{C}=\mathrm{O}$ \\
\hline 1600,1615 and 1635 (multiplet) & $1600-1640[14]$ & $v \mathrm{C}=\mathrm{C}$ \\
\hline 1460,1493 and 1535 (multiplet) & $\begin{array}{l}1565[7], 1590 \text { [13], 1450-1590 [14], 1460, } \\
1537 \text { and } 1590 \text { (multiplet) [15] }\end{array}$ & $v_{\mathrm{as}} \mathrm{COO}^{-}$ \\
\hline 1370 and 1420 (doublet) & $\begin{array}{l}1410[7,13], 1420-1450[14], 1400-1420[15], \\
1401 \text { and } 1410 \text { (doublet) }[15]\end{array}$ & $v_{\mathrm{s}} \mathrm{COO}^{-}$ \\
\hline
\end{tabular}

$v, v_{\mathrm{as}}, v_{\mathrm{s}}$ : Normal, asymmetric and symmetric stretch, respectively; $v_{\mathrm{h}}$ : high-frequency absorption. 


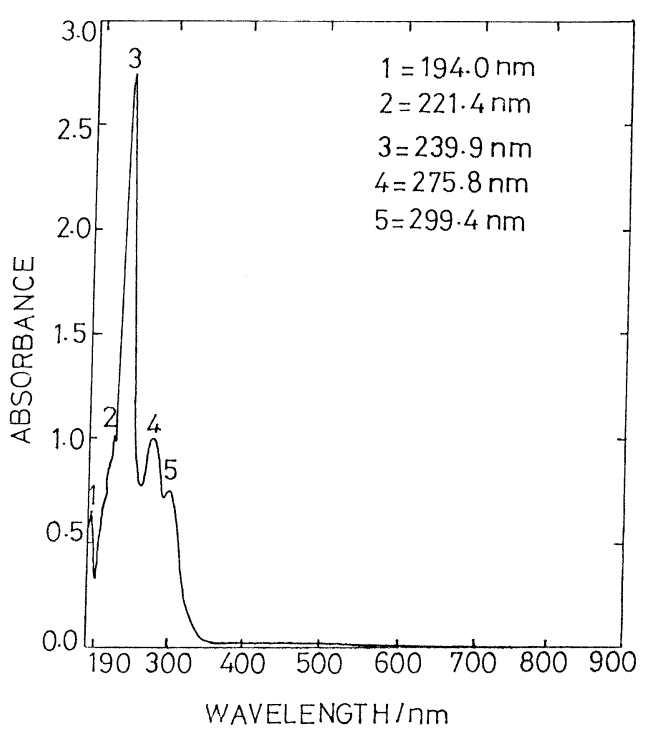

Fig. 1. Electronic (UV-VIS) spectrum of zinc(II) acetylsalicylate.

From the spectral analyses given earlier, we conclude that the mode of coordination between the $\mathrm{Zn}^{2+}$ ion and the aspirin ligand is predominantly monodentate and that the bonding is via the carboxylate $\left(\mathrm{COO}^{-}\right)$head group (Fig. 2). This is in agreement with an earlier study based on X-ray crystal structure analysis [7].

\subsection{Phase transition and thermogravimetric (TG) studies}

The phase transition studies showed that as the $\mathrm{Zn}(\mathrm{II})$ aspirin salt was being heated from room tem- perature, it did not pass directly from the solid to the liquid phase. It rather went through an intermediate mesophase (i.e. a solid-solid phase transition) around $80^{\circ} \mathrm{C}$, where the white crystals were seen to change gradually but progressively to a brown solid before finally melting rapidly to the brick-brown isotropic liquid around $134-136^{\circ} \mathrm{C}$. No formation of any liquid crystalline phases was, however, observed. Rather, the brick-brown liquid was seen to give way slowly to a brick-brown solid, with some puffing, probably resulting from the liberation of carbon dioxide. This most likely corresponds to the decomposition stage as the brick-brown solid slowly changed to a dark-brown solid between $220-260^{\circ} \mathrm{C}$ with no more puffing observed. Above $260^{\circ} \mathrm{C}$, the dark-brown solid started to blacken probably as a result of further decomposition, charring and other attendant high temperature thermal effects. These results, summarised in Fig. 3, are in concordance with earlier reports $[9,19]$ which suggested the presence of various solid-solid phase transitions for shorter chain-length $(\mathrm{C}<10)$ zinc(II) carboxylates in contrast with the results for the longer chain-length $(\mathrm{C} \geq 10)$ counterparts (soaps) which normally tend to pass directly from the solid to the liquid phase, without forming any mesophases. We agree with one of these reports [9] which explains the observed phase changes on the basis that melting is usually accompanied by chain disordering and by changes in the coordination of the metal to the carboxylate group.

The results from optical observations were complemented by those from thermogravimetry (TG) in the temperature range ca. $25-600^{\circ} \mathrm{C}$ (Fig. 4), which showed three main weight-loss phases of 8.0, 50.0 and

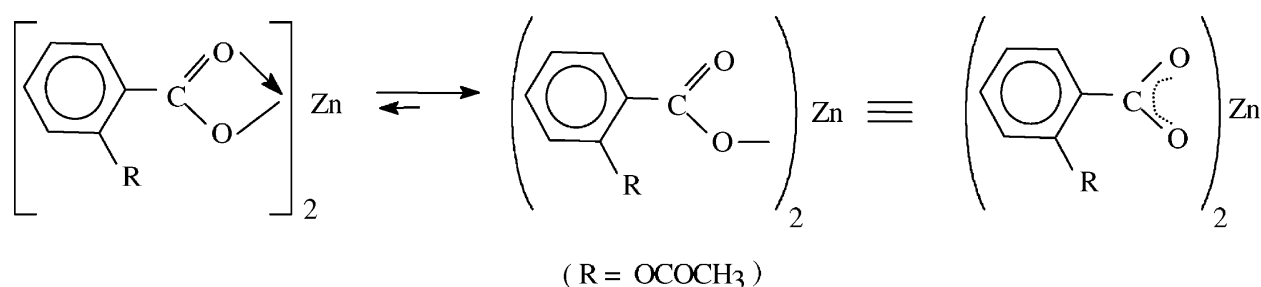

I Chelating bidentate Structure
II

Monodentate Structure (Symmetric)

Fig. 2. Coordination/bonding modes in zinc(II) acetylsalicylate. 


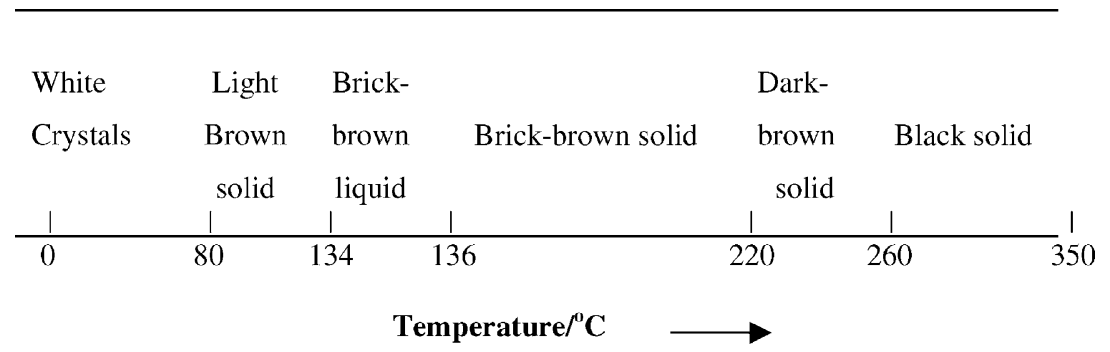

Fig. 3. Summary of the various phase transitions for zinc(II) acetylsalicylate in the temperature range ca. $25-350^{\circ} \mathrm{C}$.

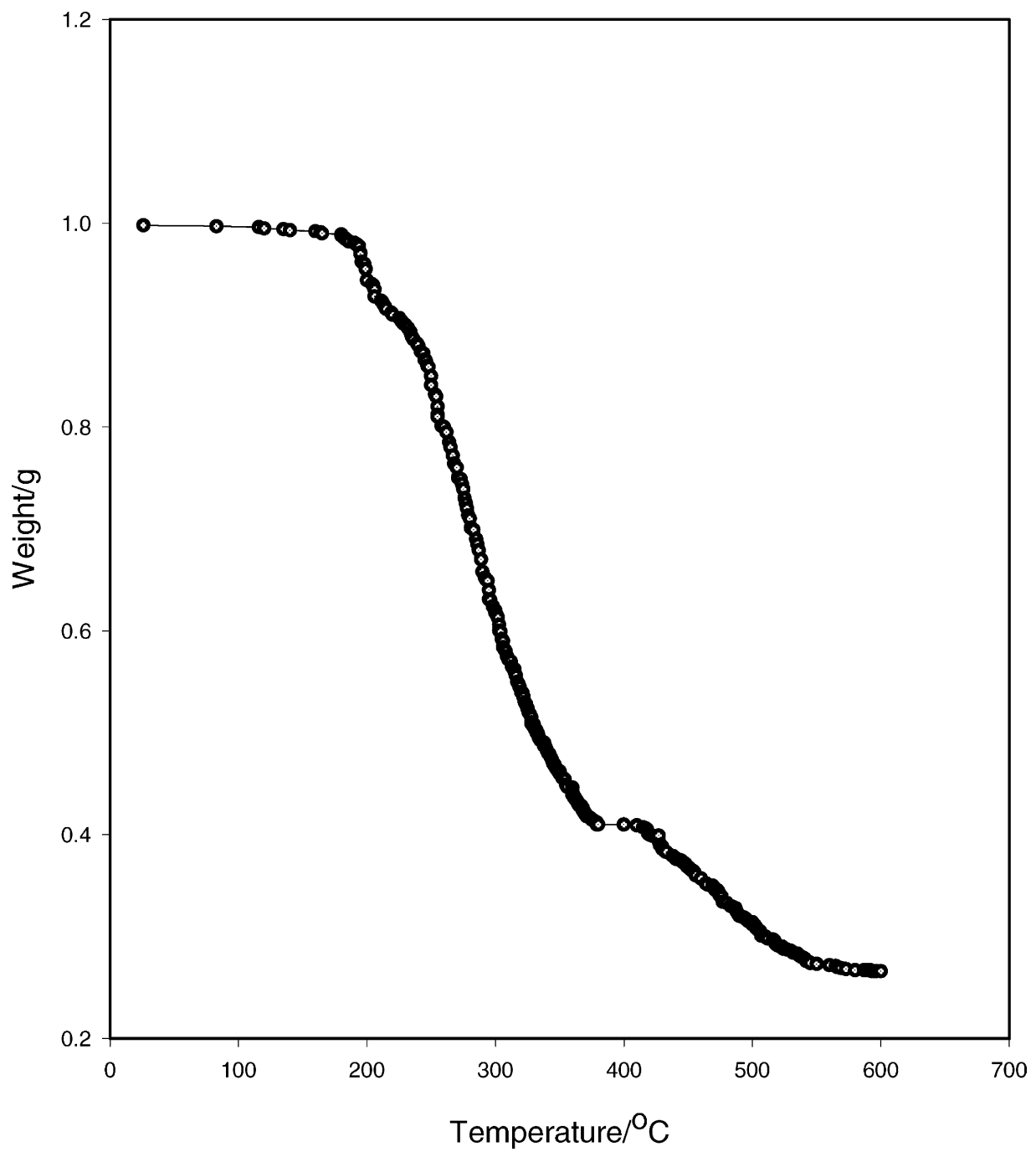

Fig. 4. Thermogravimetric (TG) curve for zinc(II) acetylsalicylate showing weight-loss as a function of temperature in the range ca. $25-600{ }^{\circ} \mathrm{C}$. 
Table 2

GC-MS identification of the six major organic products from the decomposition of zinc(II) acetylsalicylate

\begin{tabular}{lll}
\hline Product & Abundance (\%) & Confidence limit (\%) \\
\hline 4-Methoxybenzenemethanol acetate & 24.9 & 38 \\
Xanthone (xanthen-9-one) & 23.9 & 95 \\
2,4-Dimethylbenzeneamine & 9.57 & 47 \\
Benzoic acid 2-hydroxyphenyl ester (salsalate) & 7.4 & 91 \\
4-Acetamidophenyl-2-acetoxybenzoate (benorylate) & 6.8 & 64 \\
9-Phenylxanthen-9-ol & 5.6 & 64 \\
\hline
\end{tabular}

$14.0 \%$ (around 200,250 and $400{ }^{\circ} \mathrm{C}$ ) corresponding, respectively, to the elimination of $\mathrm{CO}_{2}$, xanthone and acetic acid [20].

\subsection{Product analysis}

The organic products from the decomposition of the $\mathrm{Zn}(\mathrm{acsa})_{2}\left(\mathrm{H}_{2} \mathrm{O}\right)_{2}$ were identified by $\mathrm{GC}-\mathrm{MS}$ analyses either by an automatic MS library search or by examining recorded MS spectra of the unknown GC peaks, after monitoring the peak areas. Two of the six most abundant products so identified (Table 2), namely, salsalate and benorylate, are pro-drugs of salicylic acid [10] while xanthone probably results from the cyclisation of salsalate. Apart from 4-methoxybenzene-methanol acetate and 2,4-dimethyl-benzeneamine with confidence limits below $50 \%$, all the other products listed have confidence limits above $60 \%$.

The gaseous product of decomposition was identified qualitatively to be carbon dioxide $\left(\mathrm{CO}_{2}\right)$ by bubbling it through lime water $\left[\mathrm{Ca}(\mathrm{OH})_{2}\right]$. Quantitatively, the percentage $\mathrm{CO}_{2}$, obtained from the difference in the weight of the sodalime tube before and after the passage of the gas, was found to be $10.19 \%$ which is in good agreement with the theoretical value of $10.43 \%$.

The inorganic decomposition residue (shiny-brown crystals) was found to be soluble in dilute solutions of both $\mathrm{NaOH}$ and $\mathrm{H}_{2} \mathrm{SO}_{4}$ : yielding yellow and pale yellow solutions, respectively. The zinc content of this residue, as determined quantitatively by titration with a standard solution of the disodium salt of ethylenediamine tetraacetic acid (EDTA), was $80.48 \%$, a value which compares favourably with that of $80.34 \%$ calculated from zinc in zinc oxide. This result, together with the qualitative solubility tests, show that the inorganic residue is $\mathrm{ZnO}$, which probably exists here in the non-stoichiometric form $\left(\mathrm{Zn}_{1+x} \mathrm{O}\right)$ since the crystals obtained were brown in colour and did not give the usual qualitative test for stoichiometric $\mathrm{ZnO}$ (white when cold and yellow when hot). Besides, non-stoichiometry has been reported $[21,22]$ to be responsible for the various colours (blue, green, yellow, brown, orange and red) observed for zinc oxide.

\section{Conclusion}

In this paper, we have reported the thermal behaviour of the $\left[\mathrm{Zn}(\operatorname{acsa})_{2}\left(\mathrm{H}_{2} \mathrm{O}\right)_{2}\right]$ complex with particular focus on phase transitions, pyrolysis and product identification. The complex itself was synthesized by metathesis in hot ethanol solution using stoichiometric amounts of $\mathrm{Zn}\left(\mathrm{NO}_{3}\right)_{2}$ and aspirin (as precursor), a method different from that already reported in the literature [7]. It was characterised using electronic (UV-VIS) and IR spectral analyses from which the mode of coordination between the $\mathrm{Zn}^{2+}$ ion and the aspirin ligand was established to be predominantly monodentate with the bonding being via the carboxylate $\left(\mathrm{COO}^{-}\right)$head group as earlier reported using $\mathrm{X}$-ray crystal structure analysis [7]. Results from optical studies showed that the rapid transition from the solid to the liquid phase around $134-136^{\circ} \mathrm{C}$ was preceded by a mesophase around $80^{\circ} \mathrm{C}$, with no liquid crystalline phases being formed. This result was complemented by that from TG in the temperature range ca. $25-600^{\circ} \mathrm{C}$, which showed three main weight-loss phases of 8.0, 50.0 and 14.0\% (around 200, 250 and $400{ }^{\circ} \mathrm{C}$ ) corresponding, respectively to the elimination of $\mathrm{CO}_{2}$, xanthone and acetic acid. Finally, the thermal decomposition products, as identified by a combination of instrumental (GC-MS) and wet chemical techniques, were: $\mathrm{CO}_{2}$; non-stoichiometric $\mathrm{ZnO}$ 
(most likely in the form: $\mathrm{Zn}_{1+x} \mathrm{O}$ ); and a mixture of organic compounds, consisting mainly of salicylic acid derivatives and their fragments resulting from further decomposition, charring and other attendant thermal effects at the relatively high temperatures (ca. $600^{\circ} \mathrm{C}$ ) involved. The six most abundant organic products were identified and included salsalate and benorylate which are pro-drugs of salicylic acid, a well-known pharmaceutical.

\section{Acknowledgements}

Financial support, in part, is hereby acknowledged, with deep gratitude, from The Third World Academy of Sciences (TWAS), Trieste, Italy, and The Research Council of Argentina (CONICET) for Fellowship and Research Grant Awards; and The Royal Society of Chemistry, London, for a Research Grant Award.

\section{References}

[1] S. Jourdier, Chem. Br. 35 (1999) 33.

[2] K. Dietzel, K. Brune, Differential pharmacokinetics of different salicylates: in aspirin and other salicylates, in: J.R. Vane, R.M. Botting (Eds.), Chapman \& Hall, London, 1992, pp. 107-137.

[3] J.D. Ranford, P.J. Sadler, D.A. Tocher, J. Chem. Soc. Dalton Trans. (1993) 3393.

[4] K.S. Bai, Polyhedron 2 (1983) 513.
[5] H.P. Klug, L.E. Alexander, G.G. Sumner, Acta Cryst. 11 (1958) 41.

[6] Z. Korolkiewicz, E. Hac, I. Gagalo, P. Gorczyca, A. Lodzinska, Agents Actions 26 (1989) 355.

[7] U. Hartmann, H. Vahrenkamp, Bull. Pol. Acad. Sci. Chem. 42 (1994) 161.

[8] M.S. Akanni, O.B. Ajayi, J.N. Lambi, J. Thermal Anal. 31 (1986) 131.

[9] M.S. Akanni, E.K. Okoh, H.D. Burrows, H. Ellis, Thermochim. Acta 208 (1992) 1.

[10] R.J. Lad, P.D. Funkenbusch, C.R. Aita, J. Vac. Sci. Technol. 17 (1980) 808.

[11] J.R. Vane, R.M. Botting (Eds.), Aspirin and Other Salicylates, Chapman \& Hall, London, 1992, pp. 3-16.

[12] L.F.R. Cafferata, C.W. Jefford, R.S. Rimada, Int. J. Chem. Kinet. 28 (2000) 523.

[13] H.D. Burrows, H. Ellis, Thermochim. Acta 52 (1982) 121.

[14] L.G. Wade Jr., Organic Chemistry, 3rd Edition, Prentice-Hall Englewood Cliffs, New Jersey, 1995, pp. 66-68.

[15] M.A. Mesubi, J. Mol. Struct. 81 (1982) 61.

[16] N.W. Alcock, V.M. Tracy, T.C. Waddington, J. Chem. Soc. Dalton Trans. (1976) 2243.

[17] E.A. Boudreaux, Inorg. Chem. 3 (1964) 506.

[18] H.W. Dudley, I. Fleming, Spectroscopic Methods in Organic Chemistry, McGraw-Hill, London, 1980, pp. 25-26.

[19] I. Konkoly-Thege, I. Ruth, S.O. Adeosun, S.J. Sime, Thermochim. Acta 24 (1978) 89.

[20] J.N. Lambi, A.N. Takop, P. Ndifon, Thermogravimetric Studies of $\mathrm{Zn}(\mathrm{II}), \mathrm{Cu}(\mathrm{II}), \mathrm{Fe}(\mathrm{II})$ and $\mathrm{Sn}(\mathrm{II})$ Aspirin Complexes, 2001, private communication.

[21] Scharowsky, et al. (Eds.), Handbook of Chemistry and Physics, 58th Edition, CRC Press Inc., Chevel, pp. 1977-1978.

[22] W.A. Sleight, R. Wang, J. Mater. Res. Soc. Symp. Proc. 453 (1997) 323. 